\title{
FORMA JURÍDICA E GÊNERO: UMA ANÁLISE PACHUKANIANA
}

RESUMO: O objetivo desse trabalho é relacionar a teoria marxista do direito com a questão de gênero na sociedade capitalista. Assim, irá tratar da teoria pachukaniana do direito, que deriva da análise da obra de Karl Marx, para ter instrumentais teóricos com vistas a apresentar uma hipótese sobre a causa da desigualdade de gênero existente no capitalismo e sua possível, ou não, superação. Primeiramente, tratará sobre forma jurídica e capitalismo, analisando a obra de Pachukanis, também à luz d'O capital, para compreender o papel da forma mercadoria e da forma sujeito de direito nesse modo de produção. Em segundo lugar, analisará a passagem da mulher à condição de sujeito de direito no Brasil conforme os conceitos apresentados. Por fim, relacionará a questão da forma jurídica com a possibilidade de alcance da igualdade de gênero nessa sociedade. A metodologia a ser utilizada será a revisão bibliográfica de obras que analisam a forma jurídica através do método materialista histórico-dialético e sua relação com obras que analisam gênero, principalmente no Brasil. Conclui que as mulheres passaram a ser tratadas como sujeito de direito de maneira tardia em relação aos homens e que a igualdade de gênero não poderá ser alcançada em uma sociedade de classes.

Palavras-chave: Gênero. Capitalismo. Trabalho. Direito. Keywords: Gender. Capitalism. Labor. Law. Legal form.
ABSTRACT: The aim of this paper is to relate the Marxist theory of law to the question of gender in capitalist society. Thus, it will deal with Pachukanis' theory of law, which derives from the analysis of Karl Marx's work, to have theoretical tools to present a hypothesis about the cause of gender inequality in capitalism and its possible, or not, overcoming. First, it will deal with legal form and capitalism, analyzing the work of Pachukanis, also in the light of The capital, to understand the role of commodity form and subject form of law in this mode of production. Secondly, it will analyze the passage of the woman to the condition of subject of right in Brazil according to the presented concepts. Finally, it will relate the question of legal form with the possibility of achieving gender equality in this society. The methodology to be used will be the bibliographic review of works that analyze the juridical form through the historical-dialectical materialist method and its relation with works that analyze gender, mainly in Brazil. It concludes that women have been treated as subjects of law in a late manner in relation to men and that gender equality can not be achieved in a class society. Forma jurídica.

\footnotetext{
${ }^{1}$ Integrante do DHCTEM - Grupo de pesquisa em direitos humanos, centralidade do trabalho e marxismo, vinculado ao Departamento de direito do trabalho e da seguridade social da Faculdade de direito da Universidade de São Paulo.
} 


\section{INTRODUÇÃO}

Numerosos são os estudos realizados acerca do método marxista aplicado ao direito. Tal área de pesquisa se expandiu ainda mais com o acesso à obra de Evgeni Pachukanis ${ }^{2}$, na década de 1970 no Brasil, jurista soviético que se dedicou a estudar a teoria geral do direito e o marxismo. No mesmo sentido, muitos são os estudos acerca da posição da mulher em nossa sociedade. Os chamados estudos de gêneros avançaram nas pesquisas em língua portuguesa de maneira exponencial nas últimas décadas.

Entretanto, poucos estudiosos e estudiosas se dedicaram a aplicar o arcabouço teórico construído por Marx e Pachukanis para os estudos sobre a opressão da mulher na sociedade capitalista e a ligação entre isso e a centralidade do trabalho (alguns exemplos são: SAFFIOTI, 2013; TOLEDO, 2008; NOGUEIRA; 2011).

Nessa toada, o objetivo do presente estudo é esboçar uma análise sobre a opressão das mulheres no Brasil através do método marxista, centrando o estudo na forma jurídica, através da relação entre as normas aplicadas ao trabalho da mulher e a opressão desta na sociedade de classes. Tal pesquisa será operada principalmente pela revisão bibliográfica de autores marxistas, e a própria obra de Marx, e sua relação com estudos de gênero e direito brasileiro.

Desse modo, tratará a forma jurídica no capitalismo e suas relações com a questão da desigualdade, não olvidando a centralidade do trabalho nesse processo. Para tanto, será analisado, inicialmente, o caráter fetichista da mercadoria e sua relação com o sujeito de direito, conceito que apareceu na transição do modo de produção feudal para o modo de produção capitalista através das revoluções burguesas que consagraram o indivíduo como livre e proprietário capaz de firmar contratos em situação de igualdade com os capitalistas. Esses conceitos são importantes para discutir o trabalho da mulher na sociedade capitalista, tanto seu trabalho produtivo quanto reprodutivo (ou doméstico).

\footnotetext{
2 A primeira tradução em português da principal obra do autor, "A Teoria Geral do Direito e o Marxismo", é datada de 1977, pela Editora Centelha. Recentemente mais duas importantes traduções desse livro foram feitas para o português diretamente da língua russa, das quais destaco a edição da Editora Sundermann (PACHUKANIS, 2017). Como referência destaco a resenha de Machado (2017).
} 
A lógica da equivalência mantida através da forma do contrato e a apropriação da mais-valia pelo capitalista são questões eminentemente ligadas a esse modo de produção e que são essenciais para a compreensão das relações sociais estabelecidas entre as mulheres trabalhadoras e os donos dos meios de produção.

Após, irá se verificar historicamente a passagem da escravidão no Brasil para o mercado assalariado e suas ligações com as dificuldades sofridas pelas mulheres, principalmente as mulheres negras. Necessário, então, evidenciar os processos normativos que possibilitaram que as mulheres se tornassem sujeitos de direito, no sentido colocado acima. Nesse sentido, irá se perceber que o processo para tornar as mulheres livres, iguais juridicamente e proprietárias de sua própria força de trabalho, possibilitando que pudessem livremente a vender, no Brasil, deu-se de maneira tardia em relação ao homem.

Ou seja, a passagem das mulheres de seres dependentes e desiguais para que fossem consideradas livres, iguais e proprietárias de sua força de trabalho, capazes de firmar contratos para serem exploradas, pela forma jurídica brasileira, foi um processo mais longo do que para os homens. Além de explorada no âmbito privado - no caso das mulheres negras exploradas na produção desde o início das lavouras brasileiras - as mulheres com o tempo se tornaram livres para vender sua força de trabalho no mercado assalariado. Não se pode ignorar que o sentido dessa liberdade é de estarem livres dos meios de produção e livres para trabalhar para o capitalista que preferirem, sendo, assim, obrigadas a vender a sua força de trabalho para que pudessem sobreviver ${ }^{3}$.

Então, munidos desses conceitos, os principais resultados da pesquisa serão desenvolvidos ao relacionar a forma jurídica com o trabalho das mulheres, tanto produtivo quanto, principalmente, reprodutivo. Dessa forma, discutir-se-á acerca da possibilidade de alcance da igualdade de gênero na sociedade de classes pela teoria marxista.

Após, serão apresentadas as considerações finais sobre o tema de pesquisa, relacionando a questão da forma jurídica e suas implicações no estudo de gênero no capitalismo.

\footnotetext{
3 "Para transformar dinheiro em capital, o possuidor de dinheiro tem, portanto, de encontrar no mercado de mercadorias o trabalhador livre, e livre em dois sentidos: de ser uma pessoa livre, que dispõe de sua força de trabalho como sua mercadoria, e de, por outro lado, ser alguém que não tem outra mercadoria para vender, livre e solto, carecendo absolutamente de todas as coisas necessárias à realização de sua força de trabalho." (MARX, 2013, p. 244).
} 


\section{A DISCUSSÃO MARXISTA E PACHUKANIANA ACERCA DA FORMA JURÍDICA NO}

\section{CAPITALISMO}

Para a teoria pachukaniana, que analisa a forma jurídica a partir do método marxista, o direito é instrumento específico do capitalismo que é interdependente à forma valor (BASTOS, 2018). Destarte, para que se possa avançar na discussão sobre o significado da forma jurídica para esses dois autores é necessário entender conceitos marxistas essenciais, como a própria forma valor e a forma mercadoria (MARX, 2013).

A mercadoria, no capitalismo, é produzida para compra e venda no mercado, e não para uso do próprio produtor. A objetividade de seu valor é social, ou seja, "só pode se manifestar numa relação social entre mercadorias" (MARX, 2013, p. 125) e na medida em que são expressões da mesma unidade: o trabalho humano. Para sua produção, então, é necessário o dispêndio de trabalho humano abstrato. O processo de trabalho cria o valor, ou mais-valor, conceito sobre o qual se discorrerá mais à frente, que se incorpora nas mercadorias, as quais serão vendidas no mercado. Conforme lição de Marx, "as mercadorias não podem ir por si mesmas ao mercado e trocar-se umas pelas outras" (MARX, 2013, p. 159) ${ }^{4}$, é necessário que as pessoas sejam entendidas como iguais, livres e proprietárias. Essas pessoas são os sujeitos de direito, sobre as quais irá teorizar Evgeni Pachukanis em sua análise sobre a teoria geral do direito (PACHUKANIS, 2017), que portam as mercadorias e as trocam por outras que sejam consideradas equivalentes ${ }^{5}$ a fim de que haja circulação de riquezas. Ocorre que a valorização da mercadoria, que permite a acumulação de capital, se dá no processo de produção através da compra da mercadoria força de trabalho, e não no de circulação - ou seja, na venda no mercado com preço acima do que o vendedor o adquiriu - como a ideologia capitalista deixa parecer.

\footnotetext{
${ }^{4}$ No mesmo sentido: “(...) os trabalhos privados só atuam efetivamente como elos do trabalho social total por meio das relações que a troca estabelece entre os produtos do trabalho e, por meio destes, também entre os produtores. $A$ estes últimos, as relações sociais entre seus trabalhos privados aparecerem como aquilo que elas são, isto é, não como relações diretamente sociais entre pessoas em seus próprios trabalhos, mas como relações reificadas entre pessoas e relações sociais entre coisas" (MARX, 2013, p. 148).

5 "Somente a expressão de equivalência de diferentes tipos de mercadoria evidencia o caráter específico do trabalho criador de valor, ao reduzir os diversos trabalhos contidos nas diversas mercadorias àquilo que lhes é comum: o trabalho humano em geral" (MARX, 2013, p. 128).
} 
Desse modo, o fetichismo da mercadoria, segundo Pachukanis, completa-se a partir da noção de fetichismo do sujeito de direito ${ }^{6}$, considerando que o vendedor vai ao mercado vender sua mercadoria "escondido" na relação social das coisas a serem trocadas. Esses vendedores são, propriamente, os sujeitos de direitos, ou seja, são pessoas dotadas da subjetividade jurídica que foi desenvolvida na passagem do modo de produção feudalista para o capitalista, momento em que ocorre a dissolução das relações orgânicas patriarcais do feudalismo. O momento da transição entre modos de produção é importante para a análise da conformação da forma jurídica no capitalismo e, também, para a questão da desigualdade de gênero e, por isso, retomaremos essa discussão mais a frente. As relações sociais passaram, após essa transição, a serem baseadas na "autonomia da vontade" jurídica: todos passam a poder livremente negociar e firmar contratos, sendo considerados como iguais para tanto ${ }^{7}$.

Dessa maneira, o caráter misterioso da mercadoria se encontra com o caráter misterioso do sujeito de direito - livre, igual e proprietário - que não dispõe de nenhuma propriedade a não ser a sua capacidade de trabalhar mas que pode livremente pactuar contratos com os donos do meio de produção a partir do mesmo patamar jurídico, pois são iguais perante a forma jurídica, diferentemente de como ocorria com os servos e senhores no feudalismo. O direito, então, é entendido como uma forma de equivalência subjetiva que faz circular as próprias pessoas como mercadoria, submetendo os seres humanos a "um processo de espoliação de sua capacidade de trabalho sem, não obstante isso, perder a liberdade, a autonomia de sua vontade livre" (NAVES, 2014, p. 86).

\footnotetext{
6 "A esfera do domínio, que assume a forma do direito subjetivo, é um fenômeno social imputado ao indivíduo da mesma maneira que o valor, também um fenômeno social, é imputado à coisa, um produto do trabalho. $\mathrm{O}$ fetichismo da mercadoria completa-se com o fetichismo jurídico" (PACHUKANIS, 2017, p. 146).

7 “(...) a força de trabalho só pode aparecer como mercadoria no mercado na medida em que é colocada à venda ou é vendida pelo seu próprio possuidor, pela pessoa da qual ela é a força de trabalho. Para vendê-la como mercadoria, seu possuidor tem de poder dispor dela, portanto, ser o livre proprietário de sua capacidade de trabalho, de sua pessoa. Ele e o possuidor de dinheiro se encontram no mercado e estabelecem uma relação mútua como iguais possuidores de mercadorias, com a única diferença de que um é comprador e o outro, vendedor, sendo ambos, portanto, pessoas juridicamente iguais. A continuidade dessa relação requer que o proprietário da força de trabalho a venda apenas por um determinado período, pois, se ele a vende inteiramente, de uma vez por todas, vende a si mesmo, transforma-se de um homem livre num escravo, de um possuidor de mercadoria numa mercadoria. Como pessoa, ele tem constantemente de se relacionar com sua força de trabalho como sua propriedade e, assim, como sua própria mercadoria, e isso ele só pode fazer na medida em que a coloca à disposição do comprador apenas transitoriamente, oferecendo-a ao consumo por um período determinado, portanto, sem renunciar, no momento em que vende sua força de trabalho, a seus direitos de propriedade sobre ela" (MARX, 2013, p. 242-243).
} 
Destarte, a classe trabalhadora apenas dispõe da mercadoria força de trabalho para trocar no mercado por um equivalente em salário, o qual usará para sua subsistência e de sua família. O contrato individual de trabalho se confunde com o próprio direito de propriedade, no sentido de que "o trabalhador não tem outro 'direito' que não seja o de vender sua força de trabalho e receber o 'preço' sob a forma de salário" (EDELMAN, 2016, p. 29). Ou seja, o trabalhador e a trabalhadora possuem como propriedade apenas o próprio corpo, o qual precisam "alugar" ao capitalista (vender a força de trabalho) para prover sua sobrevivência. Segundo Edelman, nesse sentido, o contrato de trabalho reproduz a relação entre capital e trabalho e completa os direitos do trabalhador "sob a forma de salário" (EDELMAN, 2016, p. 29).

No capitalismo, então, a centralidade da vida passa a ser a própria troca de mercadorias e o direito surge, nesse contexto, como forma de organização social e de manutenção da troca de equivalentes (NAVES, 2014, p. 100). Essa ideologia do contrato passa a regulamentar todos os âmbitos da vida do sujeito de direito - que aliena a si mesmo por tempo determinado ao capitalista, o que mostra a "expressão máxima da liberdade e igualdade" no capitalismo, já que realiza completamente a "liberdade de disposição de si mesmo enquanto objeto em uma relação de absoluta igualdade com o comprador" (NAVES, 2015, p. 168).

Ou seja, o trabalhador vende a sua mercadoria força de trabalho em troca de uma mercadoria equivalente, que é o próprio dinheiro, através do preço estabelecido como salário no contrato de trabalho. O trabalhador só pode ser visto como proprietário capaz de vender sua força de trabalho quando se torna sujeito de direito. Essa é, então, uma relação social específica do capitalismo mediada pelo direito, que também é um mecanismo específico do capitalismo.

A questão é que essa, em tese, troca de equivalentes mediada pela forma jurídica encoberta o fato de que a força de trabalho é a mercadoria essencial para a produção de valor no capitalismo, já que o que cria valor é o processo de produção - incorporação do trabalho vivo nas mercadorias - e não a circulação. O preço pago pelo capitalista ao trabalhador pela sua jornada de trabalho (salário) é menor do que o valor que o 
trabalhador produz, com o auxílio dos meios de produção ${ }^{8}$. Esse é o segredo do capital: é pago ao trabalhador pela sua jornada inteira de trabalho apenas as horas que correspondam ao suficiente para mantê-lo vivo e a "sobra" produzida nas demais horas da jornada é apropriada pelo capitalista sendo denominada de "mais-valia" ou "mais-valor"9. Por isso a indicação de que a troca de equivalentes é em tese, pois o trabalhador produz mais valor em sua jornada do que o que recebe em troca na forma de salário.

O mais-valor, assim, simboliza o valor produzido pelo trabalhador e apropriado pelo capitalista. Este esforça-se ao máximo para aumentar a taxa do mais-valor, diminuindo os gastos com a produção o quanto possível, inclusive, ou principalmente, os custos com a força de trabalho. A finalidade última do capitalismo é, dessa maneira, a própria acumulação.

Algumas das possibilidades para aumentar a acumulação de mais valor são o aumento da jornada do trabalhador, da intensidade do trabalho ou a diminuição do preço pago pela própria mercadoria força de trabalho ${ }^{10}$. Nesse sentido, o trabalho produtivo é

\footnotetext{
8 "O fato de que meia jornada de trabalho seja necessária para manter o trabalhador vivo por 24 horas de modo algum---- o impede de trabalhar uma jornada inteira. (...) O valor de uso da força de trabalho, o próprio trabalho, pertence tão pouco a seu vendedor quanto o valor de uso do óleo pertence ao comerciante que o vendeu. 0 possuidor do dinheiro pagou o valor de um dia de força de trabalho; a ele pertence, portanto, o valor de uso dessa força de trabalho durante um dia, isto é, o trabalho de uma jornada" (MARX, 2013, p. 270).

${ }^{9}$ "Se não trabalhasse para o capitalista, mas para si mesmo, independentemente, ele [o trabalhador] continuaria a dedicar, mantendo-se iguais as demais circunstâncias, a mesma média diária de horas de sua jornada à produção do valor de sua força de trabalho e, desse modo, à obtenção dos meios de subsistência necessários à sua manutenção ou reprodução contínua. Mas como na parte de sua jornada de trabalho em que produz o valor diário da força de trabalho, digamos, 3 xelins, o trabalhador produz apenas um equivalente do valor já pago pelo capitalista - e, desse modo, apenas repõe, por meio do novo valor criado, o valor do capital variável adiantado -, essa produção de valor aparece como mera reprodução. Portanto, denomino 'tempo de trabalho necessário' a parte da jornada de trabalho em que se dá essa reprodução, e 'trabalho necessário' o trabalho despendido durante esse tempo. Ele é necessário ao trabalhador, porquanto é independente da forma social de seu trabalho, e é necessário ao capital e seu mundo, porquanto a existência contínua do trabalhador forma sua base.
}

O segundo período do processo de trabalho, em que o trabalhador trabalha além dos limites do trabalho necessário, custa-lhe, de certo, trabalho, dispêndio de força de trabalho, porém não cria valor algum para o próprio trabalhador. Ele gera mais-valor, que, para o capitalista, tem todo o charme de uma criação a partir do nada. A essa parte da jornada de trabalho denomino tempo de trabalho excedente [Surplusarbeitszeit], e ao trabalho nela despendido denomino mais-trabalho [Mehrarbeit] (surplus labour). (...) A taxa de mais-valor é, assim, a expressão exata do grau de exploração da força de trabalho pelo capital ou do trabalhador pelo capitalista" (g.n.) (MARX, 2013, p. 293-294).

10 "A fim de que o tempo de trabalho do operário produza valor proporcionalmente à sua duração, ele mesmo deve ser tempo de trabalho socialmente necessário. Isto é, o operário deve executar em determinado tempo a quantidade socialmente normal de trabalho útil, e por isso o capitalista obriga o operário a que seu trabalho alcance, pelo menos, o grau médio de intensidade de acordo com a norma social. Procurará aumentá-lo o mais que possa além desse mínimo, e extrair do operário, em determinado tempo, o maior trabalho possível, posto que toda intensificação do trabalho além do grau médio lhe proporciona mais-valia. Tratará, além disso, de prolongar o mais possível o processo 
uma "relação de produção especificamente social, surgida historicamente e que cola no trabalhador o rótulo de meio direto de valorização do capital” (MARX, 2013, p. 578).

Dessa forma, retornando à questão do salário, tal valor deve ser suficiente para o sustento do trabalhador e sua família, ou seja, deve ser suficiente para reproduzir a classe trabalhadora enquanto classe e enquanto pessoas individualmente consideradas. É preciso que o salário possa custear os meios de subsistência da família trabalhadora, para que ela possa comprar alimentos, roupas, remédios etc., e também possa suportar os custos de ter filhos. Quando o salário médio não é capaz de fazer frente ao sustento da classe trabalhadora a lógica de equivalência do capitalismo fica ameaçada, mesmo sendo tal conceito razoavelmente elástico. A questão é mais grave, na visão do capitalista, pelo fato de que o trabalhador deixará de consumir, diminuindo o escoamento da produção (BATISTA, 2013, p. 240-241).

Antes de encerrar a análise sobre as teorias pachukanianas e marxistas do direito, importante indicar uma discussão que está sendo feito por teóricos e teóricas marxistas e de gênero (exemplos: NOGUEIRA, 2011; MOLITOR, 2018; FEDERICI, 2015, 2017) recentemente sobre a reprodução, questão indicada brevemente acima.

A reprodução da família trabalhadora assume um nítido caráter de gênero. A mulher trabalhadora, além de estar no espaço produtivo, é responsável não só pela reprodução no sentido biológico - de aumentar a classe trabalhadora ao gerar filhos - mas também no sentido de executar os trabalhos domésticos para que as famílias sobrevivam ao preparar os alimentos, lavar as roupas etc. As atividades realizadas no âmbito privado são feitas quase em sua totalidade pelas mulheres e reproduzem a principal mercadoria do capitalismo, a força de trabalho. Portanto, importante destacar que a mera relação de equivalência de compra e venda da força de trabalho não resolve a sobrevivência da classe trabalhadora. A essencialidade do trabalho reprodutivo para a sobrevivência do modo de

\footnotetext{
de trabalho, além dos limites em que é necessário trabalhar para repor o valor do capital variável, o salário. Uma vez conseguida determinada intensidade do processo de trabalho, o capitalista procurará prolongar sua duração o mais possível; conseguida determinada duração do trabalho, esforçar-se-á por aumentar o quanto possível sua intensidade. O capitalista obriga o operário a dar a seu trabalho o nível normal, e se possível um nível superior de intensidade, e força-o, o tanto quanto possível, a prolongar o processo de trabalho além do tempo necessário para reposição do salário" (MARX, 2013, p. 18).
} 
produção capitalista, em geral, não é analisada quando se está discutindo a relação de equivalência no capitalismo.

Dessa forma, destaque-se que as mulheres não recebem pelo trabalho reprodutivo, ao menos de maneira "direta" como o salário, um equivalente pelo uso de sua força de trabalho no ambiente doméstico:

Não podemos esquecer, entretanto, que não existe a força de trabalho sem a existência do trabalhador(a), o(a) qual foi gerado(a) e mantido(a) por uma mulher. Portanto, a venda da força de trabalho do proletário(a) é garantida pelas atividades domésticas realizadas, na grande maioria das vezes, pela mulher, quer ela seja uma trabalhadora produtiva ou não (NOGUEIRA, 2011, p. 169)

O equivalente pago aos trabalhadores e às trabalhadoras na esfera vista como tipicamente produtiva considera a quantia de salário necessária para reprodução da força de trabalho no sentido de possibilitar a compra dos meios de subsistência, e não considera, ao menos de maneira clara, o trabalho doméstico necessário para que tais meios de subsistência possam ser preparados ${ }^{11}$. Até mesmo o próprio Marx, n’O capital, não reconhece que reprodução da força de trabalho envolve necessariamente "o trabalho não remunerado das mulheres" (FEDERICl, 2015, s.p.). Ao contrário, "ele insiste em retratar o assalariado como um reprodutor de si mesmo" (FEDERICI, 2015, s.p.).

Nesse sentido, a questão da reprodução da classe trabalhadora envolve gênero e forma jurídica no capitalismo, considerando que essa constatação não foi incorporada pelo direito e, convenientemente, não integra a maior parte das discussões sobre a forma jurídica como meio de garantir a relação de equivalências universal. Apesar de não ser um assunto discutido pelo teórico Pachukanis, é um assunto que foi tocado em alguns momentos por Marx e que se mostra importante para a análise que se fará no presente.

\footnotetext{
11 “Como se assegura a reprodução da força de trabalho? Ela é assegurada em se fornecendo à força de trabalho os meios materiais para sua reprodução: através dos salários. Os salários aparecem na contabilidade de cada empresa, mas como 'capital aplicado em mão-de-obra', e não como uma condição de reprodução material da força de trabalho. Entretanto, é exatamente assim que ele 'funciona', pois os salários representam apenas a parcela do valor produzido pelo dispêndio da força de trabalho, indispensável a sua reprodução: ou seja, indispensável à recomposição da força de trabalho do assalariado (os meios para pagar a moradia, a alimentação e o vestuário, em suma, para permitir que o assalariado torne a se apresentar no portão da fábrica no dia seguinte - e em todos os outros dias que deus lhe conceder); convém acrescentar: indispensável para criar e educar os filhos em quem o proletário se reproduz (em $\mathrm{x}$ exemplares em que $x=0,1,2$ etc.) como força de trabalho." (g.n.) (ALTHUSSER, 1996, p. 107)
} 


\section{A PASSAgEM DA MULHER PARA A CONDIÇÃO DE SUJEITO DE DIREITO NO} CAPITALISMO BRASILEIRO

Apresentados os conceitos essenciais que serão utilizados para a análise do tratamento da mulher enquanto sujeito de direito no Brasil, passa-se a analisar brevemente o contexto histórico brasileiro que será útil para o desenvolvimento dos objetivos propostos no presente.

Assim, necessário iniciar a análise do contexto brasileiro a partir da abolição da escravatura, que se deu em 1888, considerando que esse é um marco formal para o início do tratamento dos trabalhadores como sujeito de direito. A partir desse momento, a força de trabalho brasileira passou a ser "moldada" ao trabalho livre. Segundo Kowarick (KOWARICK, 1994), as relações de produção baseadas na escravidão demonstravam para a parcela livre da população que o trabalho era uma forma de existência degradada. Tal parcela da população preferia se transformar em "ralé", baseando sua sobrevivência em uma economia natural de subsistência, do que se sujeitar ao trabalho baseado na obediência ao senhor latifundiário ${ }^{12}$.

Nesse sentido, mesmo com o declínio da escravidão no Brasil, dificilmente os donos de terras conseguiam atrair a população livre para trabalhar nas lavouras e, assim, os grandes proprietários passaram a "importar" força de trabalho da Europa.

É nessa passagem do trabalho escravo para a contratação de trabalhadores assalariados que começa a surgir, no Brasil, os sujeitos de direito livres e iguais juridicamente para vender sua mercadoria força de trabalho. Nesse período, os escravos não foram contratados, em sua maioria, como trabalhadores livres e a força de trabalho nacional, como dito acima, não queria se sujeitar às péssimas condições de trabalho nas lavouras. Das sobras da força de trabalho resultante desse processo de "importação" de estrangeiros para trabalhar nas lavouras brasileiras que a nascente indústria nacional se aproveitou para expandir o capital fabril, o qual começou a surgir entre o final do século

\footnotetext{
12 "Na medida em que as relações de produção fossem marcadas pelos rigores e horrores imperantes no regime de trabalho escravo, nada mais natural que a população livre encarasse o trabalho como alternativa mais degradada da existência. Os livres transformaram-se em ralé, antes de se submeterem às modalidades de exploração, cujo paradigma estavam alicerçado nos grilhões e chibatas das senzalas. Antes a sobrevivência autônoma, numa espécie de economia natural de subsistência, do que a sujeição a regras de obediência e disciplina, nas quais prevalece um arbítrio, que está contaminado pelo uso e abuso inerente ao cativeiro (...)" (KOWARICK, 1994, p. 55).
} 
XIX e início do XX. Inicialmente a mão de obra estrangeira foi preferida para contratação nas fábricas pois eles já estariam "acostumados" ao trabalho livre. Inclusive, até a década de 1920 os imigrantes ainda eram maioria nas fábricas brasileiras em comparação à mãode-obra nacional.

Para uma análise de gênero e forma jurídica não se pode olvidar, nesse sentido, a questão da mulher negra e, por isso, deve ser levada em consideração a herança escravista. A passagem do trabalho escravo para o trabalho livre é essencial para análise da situação das mulheres no direito do trabalho brasileiro.

As mulheres escravas estavam completamente integradas ao trabalho tanto nas lavouras quanto nas casas dos senhores. Assim como nos Estados Unidos que, conforme Davis, com relação ao que se esperava do trabalho de mulheres e meninas "a força e a produtividade sob a ameaça do açoite eram mais relevantes do que questões relativas ao sexo" e, por esse motivo, "a opressão das mulheres era idêntica à dos homens" nas lavouras. As mulheres sofriam ainda mais considerando que além da produtividade esperada "eram vítimas de abuso sexual e outros maus-tratos bárbaros que só poderiam ser infligidos a elas" (DAVIS, 2016, p. 19).

Não se pode dizer, assim, que as mulheres simplesmente "entraram" no mercado de trabalho recentemente, conforme o seguinte excerto de Saffioti:

A mulher das camadas sociais diretamente ocupadas na produção de bens e serviços nunca foi alheia ao trabalho. Em todas as épocas e lugares tem ela contribuído para a subsistência de sua família e para criar a riqueza social (g.n.) (SAFFIOTI, 2013, p. 61).

Nesse mesmo sentido, de acordo com Telles, no contexto do início da industrialização brasileira, poucas oportunidades eram conferidas às mulheres que precisavam trabalhar, em geral negras, ex-escravas, pobres e imigrantes. Essas mulheres precisaram disputar postos desqualificados e mal pagos para que conseguissem sobreviver quase sempre em atividades de subsistências desvalorizadas na economia de exportação que visava lucro, como as ocupações "com a cozinha, o pequeno artesanato doméstico, a limpeza da casa, a lavagem, a costura, o engomado das roupas e o cuidado de crianças" (TELLES, 2013, p. 47). 
Destarte, o trabalho doméstico é um dos guetos ocupacionais (SOUZA-LOBO, 2011) em que se concentram as mulheres. Mais especificamente, as mulheres negras em sua maioria. Adiantando no período histórico, a própria profissionalização do trabalho doméstico e a demora em igualar os direitos dessas trabalhadoras aos direitos de outros trabalhadores é uma pista sobre o tratamento diferenciado dado pela forma jurídica brasileira a homens e mulheres. A emenda constitucional $n-72$, que passou a igualar os direitos das empregadas domésticas com os direitos dos demais trabalhadores, foi promulgada apenas em $2013^{13}$.

Necessário, também, notar que mesmo quando não são contratadas profissionais domésticas para executar o trabalho reprodutivo, são as mulheres do próprio núcleo familiar de maneira não remunerada que cumprem tais atividades. Essa é uma das dificuldades para o tratamento jurídico igualitário entre homens e mulheres na sociedade capitalista.

Retomando a discussão histórica, após a abolição da escravatura, necessária a análise do decreto federal no $16.300 / 1923^{14}$, que estabelece, pela primeira vez para todo o território nacional ${ }^{15}$, a licença maternidade, sendo "facultado [às gestantes] o repouso de trinta dias antes e trinta dias depois do parto"16. A maternidade foi a primeira proteção

\footnotetext{
13 "É muito sintomático constatar-se que os trabalhadores domésticos, na ocorrência essencialmente de trabalhadoras, não tenham reconhecidos uma série de direitos sociais como os de trabalhadores urbanos e rurais, a não ser a 'garantia de salário, nunca inferior ao mínimo, para os que percebem remuneração variável' e que nenhum limite de tempo de trabalho seja para eles fixado. Entende-se, portanto, que o trabalho doméstico é um labor que se confunde com o tempo biológico e por isso dificilmente pode ser limitado em termos de jornada de trabalho. Se tal é o caso para as 'trabalhadoras', não é necessário codificá-lo para as donas de casa” (SOUZA-LOBO, 2011, p. 239).

${ }^{14}$ BRASIL. Decreto federal n.o 16.300, de 31 de dezembro de 1923. Approva o regulamento do Departamento Nacional de Saude Publica. CLBR, Rio de Janeiro, RJ, 1923. Disponível em: <http://www.planalto.gov.br/ccivil_03/decreto/19101929/D16300.htm>. Acesso em: 3 jul. 2018.

${ }^{15}$ A primeira norma brasileira que faz referência à questão da maternidade é a lei estadual no 1.596 , de 29 de dezembro de 1917, do estado de São Paulo. Tal lei prevê no seu artigo 95 que "As mulheres, durante o ultimo mez de gravidez e o primeiro do puerperio, não poderão trabalhar em quaesquer estabelecimentos industriaes" (sic).
}

SÃO PAULO (Estado). Lei n.o 1.596, de 29 de dezembro de 1917. Reorganisa o Serviço Sanitario do Estado. Secretaria dos Negocios do Interior, São Paulo, SP, 7 jan. $1918 . \quad$ Disponível em: <http://www.al.sp.gov.br/repositorio/legislacao/lei/1917/lei-1596-29.12.1917.html>. Acesso em: 3 jul. 2018.

${ }^{16}$ Art. 345. Nos estabelecimentos de industria e comercio, em que trabalham mulheres, ser-lhes-á facultado o repouso de trinta dias antes e trinta dias depois do parto.

Art. 348. As empregadas ou operarias, que amamentem os filhos, facultarão os ditos estabelecimentos o ensejo necessario ao cumprimento desse dever. 
fornecida pelo direito brasileiro ao trabalho das mulheres, sendo, então, a primeira vez que o trabalho das mulheres foi visto como diferenciado em relação ao trabalho dos homens (MOLITOR, 2018, p. 74).

Após pouco mais de uma década, o Decreto Federal ํo $21.417 \mathrm{~A}^{17}$, publicado em 1932, assegurou também a proteção à maternidade e a equiparação salarial às mulheres, ao menos formalmente:

Art. 10 Sem distinção do sexo, a todo trabalho de igual valor correspondente salário igual.

Art. 70 Em todos os estabelecimentos industriais e comerciais, públicos ou particulares, é proibido o trabalho à mulher grávida, durante um período de quatro semanas, antes do parto, e quatro semanas depois. (...)

Art. 9o Enquanto afastada do trabalho por força do disposto no art. 70 e respectivos parágrafos, terá a mulher direito a um auxílio correspondente à metade dos seus salários, de acordo com a média dos seis últimos meses, e, bem assim, a reverter ao lugar que ocupava.

Art. 13을 Aos empregadores não é permitido despedir a mulher grávida pelo simples fato da gravidez e sem outro motivo que justifique a dispensa.

Conforme comentado anteriormente, as mulheres trabalhadoras em geral estavam alocadas em trabalhos precarizados, com menores salários e sem proteção específica do direito do trabalho, o que nos leva à conclusão de que as mulheres não eram tratadas pela forma jurídica como sujeitos de direito completos, de acordo com a teoria pachukaniana que foi apresentada. Ou seja, as mulheres não eram consideradas livres, iguais e proprietárias de sua força de trabalho tanto quando os homens. Inclusive, era necessário que o marido ou pai da mulher autorizasse que ela pactuasse um contrato individual de trabalho - veremos que essa normativa foi revogada de maneira relativamente recente apenas -, o que demonstra que a transição do Brasil para uma forma jurídica perfeitamente conformada nos moldes criticados pela teoria geral do direito pachukaniana foi se construindo no século XX.

\footnotetext{
Art. 349. Taes estabelecimentos deverão organizar «caixas a favor das mães pobres»; providenciarão de qualquer modo para que as operarias possam, sem prejuizo, dispensar cuidados aos filhos.

Art. 350. Para o fim de proteger as crianças haverá créches, ou salas de ammamentação, situadas proximo da séde dos trabalhos, nas quaes as mães, duas ou tres vezes, em intervallos regulares, ammamentarem seus filhos. (sic)

${ }^{17}$ BRASIL. Decreto n.o 21.417, de 17 de maio de 1932. Regula as condições do trabalho das mulheres nos estabelecimentos industriais e comerciais. Diário Oficial da União, Brasília, DF, 19 mai. 1932. Disponível em: <http://www2.camara.leg.br/legin/fed/decret/1930-1939/decreto-21417-17-maio-1932-559563-publicacaooriginal81852-pe.html>. Acesso em: 3 jul. 2017.
} 
Com relação ao decreto de 1932, percebe-se que no mesmo momento em que a mulher é reconhecida como sendo diferenciada em relação ao homem enquanto força de trabalho, ao ser estabelecido em lei tratamento especial à maternidade, também se passou a considerar como não sendo permitido juridicamente a diferenciação salarial entre homens e mulheres para a mesma função na produção, o que "eleva" o status do trabalho da mulher a ser equiparado ao trabalho dos homens. Seria, esse, um primeiro passo para a conquista da igualdade formal entre homens e mulheres trabalhadores.

Foi um processo longo para que forma jurídica passasse a considerar as mulheres como livres, iguais e proprietárias, dificultando a venda da força de trabalho de metade da população brasileira e formando exército de reserva que passaria a ser utilizado quando fosse de interesse do próprio capital. Segundo Saffioti, a sociedade de classes apesar de privar as mulheres da igualdade de gênero - não só de fato como também no âmbito da forma jurídica - foi a primeira sociedade humana que conseguiu eliminar uma real desvantagem das mulheres com relação aos homens, que seria a força física, através da técnica e da maquinaria (SAFFIOTI, 2013, p. 108-109).

Sobre a equiparação salarial entre os gêneros estabelecida juridicamente: o trabalho abstrato, conforme teoria marxista, seria vendida e comprada, em tese, pelo mesmo valor de troca ${ }^{18}$. O direito, como forma social de equivalência subjetiva autônoma, faz parecer que os trabalhadores e as trabalhadoras são iguais. Entretanto, o capital se utiliza de vários instrumentais que visam ao rebaixamento dos salários - o preço pago pela utilização da força de trabalho - e um deles é o gênero da classe trabalhadora ${ }^{19}$.

Ao forçar a entrada da mulher no mercado de trabalho fabril assalariado, já que, como dito acima, as mulheres sempre estiveram integradas ao trabalho nas lavouras, 0 capital passou a utilizar não só o trabalho do homem, mas também o trabalho de toda a família. O salário, nesse sentido, é rebaixado ao mínimo para a sobrevivência da família

\footnotetext{
18 “Na situação da mulher não se expressa, pois, apenas a contradição que diz respeito a uma igualdade de status jurídico em contraposição com a desigualdade gerada pela divisão da sociedade em classes sociais, mas, ainda, pela contradição inerente ao privilegiamento de fato e de direito dos representantes do sexo masculino numa sociedade que se havia instituído em nome da igualdade (pelo menos jurídica) de seus membros" (SAFFIOTI, 2013, p. 108).

19 "Economicamente, a exigência mais elementar não é o direito ao trabalho ou a receber salários iguais pelo serviço prestado - as duas reivindicações reformistas tradicionais - mas o direito ao trabalho igual. Atualmente, as mulheres realizam trabalhos não especializados, sem caráter criador, que podem ser vistos como "extensões" de seu papel familiar expressivo" (MITCHELL, 2006, p. 226).
} 
trabalhadora. Se apenas o homem trabalhasse de maneira assalariada, o capitalista precisaria pagar uma quantia suficiente para que ele sustentasse toda a sua família. Se o homem, a mulher e os filhos trabalham, o capitalista pode dividir o salário que seria pago por uma jornada ao homem entre todos os membros da família. Assim, o capitalista ganha no mínimo mais uma jornada de trabalho (da esposa) e continua fornecendo o equivalente pelo trabalho de apenas uma jornada ${ }^{20}$. Para que isso seja feito são fornecidas as mais variadas explicações ideológicas, conforme elucidado pelo excerto abaixo da autoria de Toledo:

O empregador se aproveita do problema de gênero (ser mulher) para não dar-lhe o emprego (poderá ficar grávida) porque existe abundância de mão-de-obra. Se houvesse pleno emprego, uma plena demanda de mão-de-obra, dificilmente o problema de gênero seria empecilho para sua contratação. $O$ que é trabalho 'feminino' e 'masculino' é definido a partir da necessidade do capital de auferir mais lucro. Ele utiliza a força de trabalho disponível, aproveitando inclusive suas diferenciações internas (entre sexo, idade, cor etc.) para este ou aquele emprego, de forma a aumentar seu rendimento. (TOLEDO, 2008, p. 44)

Em uma situação de escassez de força de trabalho, conforme a autora sugere, o capitalista precisa melhorar as condições para o trabalhador, aumentando o preço do salário, para atrair a mão-de-obra. Entretanto, em geral, existe um exército de reserva que justifica a baixa dos salários de todos os membros da classe trabalhadora ${ }^{21}$, utilizando, assim, o trabalho desvalorizado de alguns membros dessa classe, como o trabalho das

\footnotetext{
20 "O valor da força de trabalho estava determinado pelo tempo de trabalho necessário à manutenção não só do trabalhador adulto individual, mas do núcleo familiar. Ao lançar no mercado de trabalho todos os membros da família do trabalhador, a maquinaria reparte o valor da força de trabalho do homem entre sua família inteira. Ela desvaloriza, assim, sua força de trabalho. É possível, por exemplo, que a compra de uma família parcelada em quatro forças de trabalho custe mais do que anteriormente a compra da força de trabalho de seu chefe, mas, em compensação, temos agora quatro jornadas de trabalho no lugar de uma, e o preço delas cai na proporção do excedente de mais-trabalho dos quatro trabalhadores em relação ao mais-trabalho de um. Para que uma família possa viver, agora são quatro pessoas que têm de fornecer ao capital não só trabalho, mas mais-trabalho" (MARX, 2013, p. 468).

21 "A incorporação da mulher à fábrica, e também da criança, desvalorizou o trabalho masculino e aumentou o grau de exploração, agora não mais do operário individual, mas de toda a família operária. Marx explica como o valor da força de trabalho passou a ser determinado pelo tempo de trabalho indispensável para a manutenção de toda a família operária, e não mais apenas do operário adulto individual. Ao lançar no mercado de trabalho todos os indivíduos da família, a máquina distribuiu entre toda a sua família o valor da força de trabalho de seu chefe, desvalorizando-a" (TOLEDO, 2008, p. 38-39).
} 
mulheres e no caso do Brasil também das pessoas negras, por exemplo, para rebaixar o salário de todos $^{22}$.

A forma jurídica "concede", nesse sentido, às mulheres trabalhadoras a equiparação salarial com relação aos homens. Mas, como forma capitalista que é, não consegue ir além da formalização jurídica da igualdade, tornando as mulheres também sujeito de direito, mesmo que de forma tardia em comparação ao homem trabalhador.

Ou seja, com o desenvolvimento do capitalismo brasileiro, normas que visavam a equiparação dos direitos das mulheres em relação ao homem foram sendo produzidas.

Seguindo no tempo, apenas em 1989 foi revogado expressamente ${ }^{23}$ o artigo 446 da Consolidação das Leis do Trabalho que previa que o marido ou o pai da mulher poderiam pleitear a rescisão de seu contrato de trabalho para não ameaçar os vínculos da família ${ }^{24}$. Não é possível o tratamento das mulheres como sujeitos de direito se são proibidas de dispor da própria força de trabalho de maneira livre.

Além das questões apontadas de normas brasileiras que não tratavam o trabalho da mulher como igual em relação ao do homem - um contrassenso se pensar no conceito marxiano de trabalho abstrato - mesmo com a equiparação formal dos salários, as mulheres são continuaram segregadas em funções "femininas" e tais funções são menos valorizadas do que as funções "neutras" ou "masculinas". Dessa maneira, a segregação ocupacional ocasiona a disparidade entre salários entre homens e mulheres, mesmo sendo

\footnotetext{
22 "As fronteiras da masculinidade e da feminilidade sociais são relativamente móveis e, até certo ponto, parecem depender das exigências do sistema produtivo em cada período histórico" (HIRATA, 2002, p. 268).

"Sempre que haja necessidade premente de baixar os custos da produção, seja em virtude de atravessar a sociedade o período de acumulação originária, seja pela necessidade de elevar seu ritmo de crescimento econômico, o recurso ao emprego maciço da força de trabalho feminina tem-se revelado extremamente vantajoso para os empreendedores capitalistas. Não fosse a reação societária à substituição da mão de obra masculina pela feminina, e os empresários poderiam utilizar, em larga escala e com nítidas vantagens, força de trabalho da mulher quer no período de constituição de uma economia capitalista, quer em sua fase de desenvolvimento" (SAFFIOTI, 2013, p. 332).

${ }^{23} \mathrm{O}$ artigo 446 da Consolidação das Leis do Trabalho brasileira foi revogado tacitamente pela lei federal no 4.121/1962 e, expressamente, apenas no final da década de 1980, pela lei federal no 7.855/1989.

${ }^{24}$ Art. 446 da CLT (revogado): Presume-se autorizado o trabalho da mulher casada e do menor de 21 anos e maior de 18. Em caso de oposição conjugal ou paterna, poderá a mulher ou o menor recorrer ao suprimento da autoridade judiciária competente.

Parágrafo único: Ao marido ou pai é facultado pleitear a recisão do contrato de trabalho, quando a sua continuação for suscetível de acarretar ameaça aos vínculos da família, perigo manifesto às condições peculiares da mulher ou prejuízo de ordem física ou moral para o menor.
} 
as funções consideradas "masculinas" e "femininas" completamente diferentes de um país para outro (TOLEDO, 2008, p. 62).

Essa é mais uma forma do modo de produção capitalista de diferenciar os sujeitos de direito dentro da própria classe trabalhadora e assim piorar as condições de trabalho de todos.

Mesmo com o auxílio do direito do trabalho estabelecendo normas com o objetivo, ao menos em tese, de diminuir essas desigualdades, não é da natureza do próprio capitalismo permitir que a igualdade entre homens e mulheres seja alcançada, conforme argumentado no presente - assim como a igualdade entre as classes.

\title{
4 A FORMA JURÍDICA E A IGUALDADE DE GÊNERO
}

Considerando essas questões, a sociedade de classes capitalista divide as pessoas e aprofunda preconceitos já existentes, utilizando-os como meio de aumentar a acumulação de mais-valia, conforme o seguinte trecho de Saffioti:

\begin{abstract}
Ilusoriamente, tem-se acreditado que o desenvolvimento das forças produtivas elimina a utilização dos fatores naturais [como gênero e raça] como justificativas da marginalização de enormes contingentes humanos quer do sistema de produção, quer da estrutura de poder da sociedade. Todavia, é possível distinguir, no refinamento cada vez maior das técnicas sociais, a orientação do comportamento humano por vias e para modalidades que, embora lhe imprimam o caráter aparente de conduta voluntária, encobrem desígnios não explicitados, mas atuantes, de preservar o domínio das camadas privilegiadas (SAFFIOTI, 2013, p. 329).
\end{abstract}

Ideologicamente, o capitalismo sempre se utilizou da separação entre o público e o privado, desenvolvido na transição entre modos de produção, para confinar a mulher no espaço doméstico. No feudalismo todos os integrantes da casa precisavam contribuir igualmente para a sobrevivência do grupo. Toda a família serva estava envolvida na produção de alimentos para sobrevivência. Não havia separação estanque entre o ambiente doméstico e o ambiente da produção. O próprio advento do capitalismo é uma representação da progressiva diminuição das funções que eram desempenhadas produtivamente pelas mulheres (SAFFIOTI, 2013, p. 331).

A passagem do modo de produção feudal para o capitalismo mostra como as desigualdades permaneceram e foram apropriadas pelo capitalismo para aumento da 
possibilidade de acumulação. Nessa toada, importante a teoria de Federici acerca da revisão histórica desse momento de transição e a importância da caça às bruxas na idade média para a conformação da sociedade patriarcal capitalista (FEDERICI, 2017). Segundo essa autora, no início da idade média o trabalho das mulheres não era tão desvalorizado quanto no capitalismo, inclusive as "atividades domésticas não eram desvalorizadas e não supunham relações sociais diferentes das dos homens" (FEDERICI, 2017, p. 53). momento chave para o aprofundamento das diferenças entre os gêneros foi o período do final do século XV - o período chamado de baixa idade média - quando estava ocorrendo uma "preparação" das forças produtivas para a transição de modo de produção ${ }^{25}$. Devido à peste negra, a quantidade de população da classe explorada - os servos - havia diminuído gravemente, o que causou "valorização" dessa escassa mão de obra, levando a classe dominante a conceder melhores condições de vida para os servos. Nesse sentido, houve necessidade de incentivar a reposição da mão de obra e desvalorizar a posição das mulheres (colocando trabalhadores contra trabalhadoras) ${ }^{26}$ para que a classe dominante conseguisse "controlar" a crise populacional.

Essa mudança de paradigma no tratamento das mulheres foi de fundamental importância para o aprofundamento da discriminação contra a mulher no próprio capitalismo, que se apropriou da opressão já existente contra as mulheres e do seu

\footnotetext{
${ }^{25}$ Marx teoriza sobre esse período no capítulo 23 d’o Capital, chamando de período de acumulação primitiva. É nesse momento que os trabalhadores começam a ser expulsos da terra, pelos "cercamentos", e obrigados a ir para os burgos. Também são editadas normas obrigando os ex-servos a trabalharem, punindo a "vagabundagem", para que a força de trabalho, nesse processo, passe a trabalhar por "vontade própria". Conforme veremos, Marx deixa de considerar nas causas para a passagem de modo de produção a questão do trabalho e da opressão das mulheres, que será essencial para o empobrecimento e maior exploração de toda a classe trabalhadora. Nesse sentido: “As mulheres também se viram prejudicadas pelos cercamentos, porque assim que a terra foi privatizada e as relações monetárias começaram a dominar a vida econômica, elas passaram a encontrar dificuldades maiores dos que as dos homens para se sustentar, tendo sido confinadas ao trabalho reprodutivo no exato momento em que este trabalho estava sendo absolutamente desvalorizado" (FEDERICl, 2017, p. 144).

${ }^{26}$ Todavia, no final do século XV foi posta em marcha uma contrarrevolução que atuava em todos os níveis da vida social e política. Em primeiro lugar, as autoridades políticas empreenderam importantes esforços para cooptar os trabalhadores mais jovens e rebeldes por meio de uma maliciosa política sexual, que lhes deu acesso a sexo gratuito e transformou o antagonismo de classe em hostilidade contra as mulheres proletárias. Como demonstrou Jacques Rossiaud em Medieval Prostitution (1998) [A prostituição medieval], na França, as autoridades municipais praticamente descriminalizaram o estupro nos casos em que as vítimas eram mulheres de classe baixa. (...) os resultados foram destrutivos para todos os trabalhadores, pois o estupro de mulheres pobres com consentimento estatal debilitou a solidariedade de classe que se havia alcançado na luta antifeudal. (...) A legalização do estupro criou um clima intensamente misógino que degradou todas as mulheres, qualquer que fosse sua classe. Também insensibilizou a população frente à violência contra as mulheres, preparando o terreno para a caça às bruxas que começaria nesse mesmo período (FEDERICI, 2017, p. 103-104).
} 
confinamento no espaço privado, além da desvalorização das atividades domésticas, para aumentar a exploração de toda a classe trabalhadora. Nessa toada, sem trabalho doméstico "gratuito" executado pelas mulheres, não haveria a possibilidade de incremento da extração de mais-valia no espaço produtivo.

Assim, o modo de produção capitalista passa a impor a separação entre público e privado com a criação das manufaturas e, após, as fábricas, o que segrega a própria classe trabalhadora $^{27}$. Conforme vimos acima, no próprio capitalismo não foram todas as mulheres que foram colocadas no ambiente doméstico no início, já que, por exemplo, as mulheres escravas estavam incorporadas ao trabalho produtivo e após a abolição foram obrigadas a continuar trabalhando para sua subsistência.

A aparente separação criada entre público e privado, considerando que os dois espaços estão completamente integrados à produção, sendo, por isso, apenas aparente, também é essencial para que se discuta a relação entre homens, mulheres e trabalho doméstico (ou reprodutivo). Afinal, conforme sugerimos acima, o ingresso maciço das mulheres como trabalhadoras assalariadas no mercado de trabalho teve o efeito de rebaixar os salários de todos, já que o capitalista pôde deixar de pagar um salário para o homem sustentar toda a família operária e passar a pagar dois salários com o mesmo objetivo, mas ganhando mais uma jornada de trabalho.

Através de tal ganho do capitalista, as mulheres passaram a não só serem responsáveis pelas atividades domésticas essenciais para a reprodução da classe trabalhadora, como preparação dos alimentos, cuidados com as roupas, cuidados com as crianças e os idosos etc., como também ingressaram nas filas de exploração das fábricas. Ocorre que as mulheres passaram a ter dupla jornada de trabalho mas são pagas diretamente apenas por uma.

\footnotetext{
${ }^{27}$ Nesse mesmo sentido, interessante deixar como referência a teoria de D’Emilio de que o capitalismo foi o modo de produção que tornou possível o surgimento de uma "identidade gay". A tese do autor é que antes do capitalismo, apesar de existirem pessoas gays e lésbicas, não era possível a expressão dessa identidade de maneira "social", considerando que as famílias viviam de maneira interdependente, não sendo possível a subsistência da classe trabalhadora sem um núcleo familiar heterossexual. A título exemplificativo veja-se o seguinte excerto: "Although there was a division of labor between men and women, the family was truly an interdependent unit of production: the survival of each member depended on the cooperation of all. The home was a workplace where women processed raw farm products into food for daily consumption, where they made clothing, soap, and candles, and where husbands, wives, and children worked together to produce the goods they consumed" (D'EMILIO, 1983, p. 469).
} 
Os trabalhadores e as trabalhadoras recebem pela sua jornada de trabalho um equivalente na forma de salário. Entretanto, conforme discorremos acima, o capitalista paga aos trabalhadores o equivalente suficiente para sua sobrevivência, que corresponde a apenas uma fração de sua jornada. O valor produzido no restante da jornada é apropriado pelo capitalista. No caso do trabalho doméstico, toda a jornada correspondente ao trabalho reprodutivo é apropriado pelo capitalista (pois o equivalente a ser pago à trabalhadora visando ao custeio de sua sobrevivência já foi pago em seu trabalho assalariado ou de seu companheiro). O que resta da jornada sem ser computado é o mais valor apropriado pelo capitalista ${ }^{28}$.

O trabalho reprodutivo, dessa maneira, faz parte do aumento de mais valor a ser acumulado pelo capitalista. O "valor essencial" capaz de garantir a sobrevivência da família trabalhadora engloba, nesse sentido, também o trabalho gratuito da mulher no âmbito doméstico.

Nesse sentido, o capital se apropria gratuitamente do trabalho de toda a classe trabalhadora, explorando as mulheres ainda mais, já que estas trabalham duas vezes. Por essa razão, o mero "pagamento" pela jornada de trabalho no âmbito doméstico das mulheres iria diminuir o mais valor extraído da classe trabalhadora, mas não acabaria com a exploração e apropriação de mais valia.

O trabalho reprodutivo é responsável pela produção da mercadoria mais essencial do capitalismo: a força de trabalho. Sem força de trabalho não é possível a acumulação de mais valia, considerando que apenas o trabalho gera valor. Todas as outras mercadorias do capitalismo são apenas instrumentos para circulação e encobrimento do fato de que é o trabalho que produz valor. E sem produção de valor não há acumulação, que é o objetivo final de todos os capitalistas.

Nessa toada, de acordo com a teoria de Pachukanis sobre a forma jurídica na sociedade capitalista, pode-se concluir que o trabalho das mulheres, quando doméstico, não integra a lógica da equivalência subjetiva de maneira clara, mas ainda, assim, integra

\footnotetext{
${ }^{28}$ Se o capitalista é responsável por garantir a reprodução da força de trabalho, deveria ele não apenas fornecer meios em dinheiro para a subsistência do trabalhador; mais do que isso, deveria providenciar o trabalho sem o qual a satisfação das necessidades materiais do obreiro não se dá. Em poucas palavras, arcar com os custos das tarefas domésticas, tornando consequente o sentido econômico-capitalista do salário" (CORREIA; BIONDI, 2011, p. 311-318).
} 
os salários da classe trabalhadora. Conforme a análise das normativas brasileiras acerca dos direitos trabalhistas das mulheres, elas foram consideradas como sujeitos de direitos completos, que vão ao mercado "livremente" trocar sua mercadoria força de trabalho (quando não utilizada no ambiente doméstico) por salário, apenas de maneira recente, com a revogação de norma sobre autorização por um homem e promulgação de lei que obrigasse aos empregadores pagar igual salário por igual trabalho.

Além disso, na economia capitalista a troca domina todo o processo de produção, através da lógica da equivalência, e, portanto, utiliza a força de trabalho de maneira que aumente seus lucros, ou seja, reduz ou prolonga as jornadas dos trabalhadores e trabalhadoras conforme a situação do mercado, além de "empregar a força de trabalho segundo as necessidades do mercado ou de atirá-la na rua" (LUXEMBURGO, 2015, p. 86). Aliada a questão de gênero no mercado de trabalho, é possível concluir que a depender dos interesses momentâneos do capital a mulher é integrada ao mercado formal de trabalho e "é expulsa quando há grande quantidade de trabalhadores compondo o exército de reserva", podendo ser "reconvocada" "em momentos cruciais para o capitalismo para promover o rebaixamento dos salários em geral" (MOLITOR, 2018, p. 2526). Conforme Toledo, o capitalismo se utiliza, então, da desigualdade de gênero "para estimular a competição entre os trabalhadores e baixar o nível de salários", já que "a mulher é sinônimo de trabalho barato" (TOLEDO, 2008, p. 40).

Em razão da história do surgimento do modo de produção capitalista e sua evolução no sentido de tornar as mulheres sujeitos de direito, para explorar sua força de trabalho de maneira formalmente correta pela forma jurídica, é possível aderir à conclusão de Saffioti de "se ordem social capitalista é compatível com a ideologia de plena igualdade entre os sexos" (SAFFIOTI, 2013, p. 159), considerando que o objetivo dos movimentos feministas seja a completa igualdade entre homens e mulheres e, nessa toada, a "conquista" de direitos civis e políticos seria uma "etapa do processo" da emancipação das mulheres (SAFFIOTI, 2013, p. 159).

Por outro lado, conforme investigação de Goldman, a tentativa de superação do modo de produção capitalista (que não foi bem sucedida no caso da União Soviética) não levará obrigatoriamente à superação da opressão das mulheres (GOLDMAN, 2014). 
Mesmo com a adoção de várias medidas visando a acabar com a desigualdade entre homens e mulheres na sociedade socialista, vários fracassos ocorreram - como por exemplo, a taxa de desemprego no início da Nova Política Econômica ter sido muito maior entre as mulheres, provocada, inclusive, pelas "características mais progressistas da legislação trabalhista soviética", como a licença-maternidade remunerada (GOLDMAN, 2014, p. 155-156).

\section{CONSIDERAÇÕES FINAIS}

Considerando as teorias apresentadas e sua relação, é possível concluir, de acordo com o método materialista histórico-dialético, que no modo de produção capitalista não será possível alcançar a igualdade entre os gêneros, assim como não será possível alcançar a igualdade entre as pessoas de modo geral. Conforme teoria marxista, esse modo de produção é baseado na acumulação de valor, o que significa que é essencial para o capitalismo que haja desigualdade. Para que haja desigualdade entre as classes, a classe dominante se utilizada de desigualdades internas da classe trabalhadora, aprofundando-as e aumentando a exploração de mais valia, como a opressão da mulher, utilizando, para isso, a forma jurídica como maneira de legitimar a suposta igualdade entre donos dos meios de produção e trabalhadores, assim como a liberdade para vender a força de trabalho, sua única propriedade.

O direito do trabalho surge em um contexto de crise para que as demandas da classe trabalhadora sejam minimamente atendidas para que o modo de produção não entre em colapso, já que são os trabalhadores que produzem valor e são essenciais para que haja acumulação. O direito do trabalho ao mesmo tempo que protege também esconde a demanda essencial de destruição do capitalismo para que a sociedade possa buscar a igualdade de fato e o fim da exploração.

Especificamente com relação às mulheres, objeto de análise no presente com o auxílio do método proposto, a forma jurídica as "protege" às custas de ideologicamente esconder questões essenciais. A própria proteção à maternidade, por exemplo, é possível dizer que trata de proteção da reposição de classe. E mesmo se tratando de uma proteção às mulheres e à reposição da família trabalhadora, é, às vezes, utilizada pelos capitalistas 
como excusa para contratar menos mulheres ou dispensá-las logos após o seu retorno ao trabalho. Outro exemplo é a proteção contra o assédio sexual. De fato é uma medida necessária para a segurança das mulheres, mas, considerando a análise marxista do capitalismo, pode-se dizer que essa medida tem como finalidade a proteção da própria produção, já que ambientes de trabalho que não sejam saudáveis provocam quedas na produtividade. Dentre outros exemplos de medidas que são importantes para os indíviduos da classe trabalhadora mas que não são suficientes para uma verdadeira emancipação da classe, ou, em verdade, que não buscam a emancipação.

Assim, a forma jurídica, que é forma capitalista por essencial, sustenta esse modo de produção que explora a classe trabalhadora. Conforme vimos discutindo no presente trabalho, não será através do direito de trabalho que se irá assegurar a proteção da mulher e do seu trabalho no capitalismo.

\section{REFERÊNCIAS}

ALTHUSSER, Louis. Ideologia e aparelhos ideológicos de Estado. In: ZIZEK, Slavoj. Um mapa da ideologia. Rio de Janeiro: Contraponto. 1996.

BASTOS, Ronaldo. A sociologia do direito de Marx: interdependência entre a forma-jurídica e a forma-valor no capitalismo. Revista Brasileira de Sociologia do Direito, v. 5, n. 1, p. 122-142, jan./abr. 2018. DOI: http://dx.doi.org/10.21910/rbsd.v5n1.2018.186.

BATISTA, Flávio Roberto. Crítica da tecnologia dos direitos sociais. São Paulo: Outras Expressões, 2013.

BRASIL. Decreto Federal n.o 16.300, de 31 de dezembro de 1923. Approva o regulamento do Departamento Nacional de Saude Publica. CLBR, Rio de Janeiro, RJ, 1923. Disponível em: <http://www.planalto.gov.br/ccivil_03/decreto/1910-1929/D16300.htm>. Acesso em: 3 jul. 2018.

BRASIL. Decreto n.o 21.417, de 17 de maio de 1932. Regula as condições do trabalho das mulheres nos estabelecimentos industriais e comerciais. Diário Oficial da União, Brasília, DF, 19 mai. 1932. Disponível em: <http://www2.camara.leg.br/legin/fed/decret/19301939/decreto-21417-17-maio-1932-559563-publicacaooriginal-81852-pe.html>. Acesso em: 3 jul. 2018.

CORREIA, Marcus Orione Gonçalves; BIONDI, Pablo. Uma leitura marxista do trabalho doméstico. Revista LTr: Legislação do Trabalho. São Paulo, v. 3, p. 311-318, 2011. 
DAVIS, Angela. Mulheres, raça e classe. São Paulo: Boitempo, 2016.

EDELMAN, Bernard. A legalização da classe operária. São Paulo: Editora Boitempo, 2016.

D'EMILIO, John. Capitalism and gay identity. In: SNITOW, Ann; STANSEL, Christine; THOMPSON, Sharon (Eds.). Powers of desire: the politics of sexuality. New York: Monthly Review, 1983. Disponível em: <https://rosswolfe.files.wordpress.com/2016/06/johndemilio-capitalism-and-gay-identity.pdf>. Acesso em: 3 jul. 2018.

FEDERICl, Silvia. Calibã e a bruxa: mulheres, corpo e acumulação primitiva. São Paulo: Elefante, 2017.

FEDERICl, Silvia. Notas sobre género en El capital de Marx. Revista Herramienta debate y crítica marxista, Buenos Aires, n. 60, Inverno de 2017. Disponível em: <http://www.herramienta.com.ar/revista-herramienta-n-60/notas-sobre-genero-en-el-

capital-de-marx>. Tradução por Giovanna Marcelino disponível em: <https://movimentorevista.com.br/2017/09/genero-o-capital-marx-feminismo-marxista/>. Acesso em: 3 jul. 2018.

GOLDMAN, Wendy. Mulher, Estado e Revolução: política da família soviética e da vida social entre 1917 e 1936. São Paulo: Boitempo/ISKRA, 2014.

HIRATA, Helena. Nova Divisão sexual do trabalho?. São Paulo: Boitempo Editorial, 2002.

KOWARICK, Lúcio. Trabalho e vadiagem: A origem do trabalho livre no Brasil. 2a Edição. Rio de Janeiro: Editora Paz e Terra, 1994.

LUXEMBURGO, Rosa. Reforma ou Revolução?. São Paulo: Expressão Popular, 2015.

MACHADO, Gustavo Seferian Scheffer. A teoria geral do direito e o marxismo e ensaios escolhidos (1921-1929), de Evgueni Pachukanis. Revista InSURgência. Brasília, ano 3, v. 3, n. 2, 2017. Disponível em: <periodicos.unb.br/index.php/insurgencia/article/ download/29498/20666>. Acesso em: 3 jul. 2018.

MARX, Karl. O Capital: crítica da economia política. Livro 1. São Paulo: Editora Boitempo, 2013.

MITCHELL, Juliet. Mulheres: a revolução mais longa. Revista Gênero, Niterói, v. 7, n. 1, p. 203-232, 2006.

MOLITOR, Thamíris Evaristo. O sujeito de direito a partir da proteção da maternidade pelo direito do trabalho brasileiro: Uma análise materialista histórico-dialética na perspectiva de gênero. 2018. 132 f. Dissertação (mestrado em direito) - Faculdade de Direito, Universidade de São Paulo, São Paulo, 2018.

NAVES, Márcio Bilharinho. A questão do direito em Marx. São Paulo: Outras Expressões; Dobra Universitário, 2014.

NAVES, Márcio Bilharinho. A 'ilusão da jurisprudência'. In: KASHIURA JR., Celso Naoto; AKAMINE JR., Oswaldo; MELO, Tarso (Org.). Para a crítica do direito: reflexões sobre teorias e práticas jurídicas. São Paulo: Outras Expressões, 2015. 
NOGUEIRA, Claudia Mazzei. O trabalho duplicado - a divisão sexual no trabalho e na reprodução:um estudo das trabalhadoras do telemarketing. 2. ed. São Paulo: Expressão Popular, 2011.

SAFFIOTI, Heleieth I. B. A mulher na sociedade de classes: mito e realidade. São Paulo: Expressão Popular, 2013.

SÃO PAULO (Estado). Lei n.o 1.596, de 29 de dezembro de 1917. Reorganisa o Serviço Sanitario do Estado. Secretaria dos Negocios do Interior, São Paulo, SP, 7 jan. 1918. Disponível em: <http://www.al.sp.gov.br/repositorio/legislacao/lei/1917/lei-159629.12.1917.html>. Acesso em: 3 jul. 2018.

SOUZA-LOBO, Elisabeth. A classe operária tem dois sexos. São Paulo: Editora Fundação Perseu Abramo, 2011.

TELLES, Lorena Féres da Silva. Libertas entre sobrados: mulheres negras e trabalho doméstico em São Paulo (1880-1920). São Paulo: Alameda, 2013.

TOLEDO, Cecília. Mulheres: o gênero nos une, a classe nos divide. 2. ed. São Paulo: Sunderman, 2008.

MOLITOR, Thamíris Evaristo. Forma jurídica e gênero: 